\title{
PALLADIO E ROMA
}

\author{
Arq. Nora Cappello ${ }^{1}$ \\ Universidade de São Paulo \\ Escola de Engenharia de São Carlos - EESC - USP \\ Departamento de Arquitetura e Urbanismo
}

\section{Palladio clássico ou anticlássico?}

Os séculos XV e XVI, especialmente entre 1420 e 1580, foram o período em que a arquitetura é reconhecida como forma de expressão cultural eminente, estritamente ligada à representação do poder, da riqueza, do prestígio, e é vista como instrumento para moldar, controlar e melhorar o caráter e a qualidade da vida tanto pública quanto privada. Nesta época os investimentos em obras artísticas e arquitetônicas assumem para a classe burguesa um caráter compensatório, enquanto para os nobres respondem a exigências de ostentação, necessárias pela obrigação da magnificência. A Igreja é geralmente a grande beneficiária: suas posses animam-se em todo lugar de uma atividade impressionante, multiplicam-se as novas igrejas, reestruturam-se as velhas, fundam-se novas capelas em cenários espetaculares. Mas o fenômeno é generalizado e luxo reina em âmbito religioso tanto quanto em âmbito civil e profano. Nas cidades assumem grande importância os edifícios de caráter cívico: a sede do município ou da senhoria, as loggie, a Casa de moeda, os palácios públicos e as torres de guarda são alguns exemplos.

Nesse cenário surgem nomes como o de Filippo Brunelleschi Leon Battista Alberti e Bramante. Mas entre tantos gênios, nasce um que sob certos aspectos pode ser considerado uma exceção: o padovano Andrea Palladio, alguém que elaborou uma teoria e a deixou por escrito em seu Tratado, que construiu edifícios privados e públicos, civis e religiosos, palácios, casas de campo, igrejas e até mesmo uma ponte, alguém que

\footnotetext{
1 Arquiteta graduada em 2003 em Arquitetura e Urbanismo na Escola de Engenharia de São Carlos, onde também trabalhou no Grupo Quadro de Pesquisa, desenvolvendo a pesquisa de Iniciação Científica "Palladio e Roma" durante aproximadamente dois anos. De 2004 a 2005 trabalhou na tradução para o português do tratado "I Quattro Libri dell'Architettura di Andrea Palladio", atualmente em fase de publicação. Desde fevereiro de 2006 é aluna de mestrado do programa de PósGraduação em Arquitetura e Urbanismo da Escola de Engenharia de São Carlos - EESC-USP com a pesquisa "Palladio e Vicenza: a construção de uma cidade através de seus edifícios".
} 
deixou a vida na arquitetura. Andrea di Pietro dalla Gondola é talvez o arquiteto mais romano desde a época dos antigos, que nasce em um dos períodos mais férteis em termos da produção artística italiana, não em Florença ou em Roma, mas numa região periférica a tudo isso, a República Vêneta. Andrea passou sua infância numa cidade armada. Em 1509, apenas um ano depois de seu nascimento, iniciou a chamada "Guerra Dei Cambrai", na qual Pádua e outras cidades enfrentaram Veneza junto com o Papa e as potências européias. Pádua viu-se imersa numa alternância de conquistas e reconquistas que a deixariam falida e em ruínas. A guerra termina em 1517. Por essa época vivia em Pádua alguém que certamente teria grande influência sobre os estudos e o interesse do jovem Dalla Gondola pela arquitetura: Alvise Comaro era um dono de terras com pretensões de aristocrata, que redigiu um breve tratado dando conselhos práticos sobre como constituir uma casa cômoda e barata e, em colaboração com o pintor Giovanni Maria Falconetto, desenhou para a sua casa de Pádua uma Loggia e um Odeon. Andrea acabava de entrar em contato, mesmo que indiretamente, com o novo estilo criado em Roma por Bramante.

A influência prática do duo Cornaro - Falconetto une-se à do teórico bolonhês Sebastiano Serlio, chegado de Roma ao Veneto para tomar anotações sobre edifícios que seriam incluídos em seu tratado. Sabese que Palladio leu o Terceiro e o Quarto Livro de Serlio, pelos quais entrou em contato mais aprofundado com a arquitetura romana. Em 1524, Andrea rompe o contrato que o unia a seu patrão em Pádua e foge para Vicenza, onde trabalha durante 14 anos como aprendiz e assistente de Girolamo Pittoni e Giovanni di Piedemuro, cortadores de pedra. Vicenza era então uma cidade que compensava a modéstia de seu esplendor com um especial interesse pela arquitetura como meio para aumentar esse esplendor. A lista de mecenas que Palladio incluirá em seu Tratado demonstra a sintonia da cidade com seus arquitetos e o afã de todos para tornar-se uma terra que pudesse brilhar de luz própria e não uma simples cidadezinha resignada a viver à sombra da deslumbrante Veneza.

Aos 30 anos, Andrea é chamado a trabalhar para o Conde Giangiorgio Trissino na construção da Loggia para a vila deste em Cricoli, próximo a Vicenza. A figura de Trissino foi determinante na vida do arquiteto em muitos aspectos. Trissino era um aristocrata e tinha feito parte do restrito círculo cultural do papa Leão X Médici e que, depois de perder seu poder devido à dominação veneziana teve que exilar-se em Roma. Ali conheceu Rafael e aprofundou seus estudos da tradição antiga ao mesmo 
tempo em que se empenhava num poema épico dedicado ao imperador Carlos V, "Italia Liberata Dai Godi". É neste poema que aparece um mensageiro com um nome surgido das artes da guerra e da sabedoria: Pallas Atenea. É esse o nome que mais tarde inspirará o apelido dado ao jovem padovano e que será aquele que o arquiteto gravará na história da arquitetura: Andrea Palladio.

Trissino apresentará seu protegido nos círculos intelectuais, orientará suas leituras sobre a arquitetura - muito provavelmente foi Trissino quem guiou Palladio em suas primeiras leituras de Vitrúvio -, a engenharia, a topografia antiga e o levará àquela que para qualquer leitor desse tipo de obras era o centro do universo: Roma. Ali Palladio conhece com seus olhos aquilo que até então conhecera apenas por livros como o terceiro e o quarto livro do "Tratado De Arquitetura" de Sebastiano Serlio.

As viagens para Palladio tornaram-se um meio de aprendizagem: ele não só via os monumentos antigos como tinha o cuidado de medi-los e reproduzi-los em seus desenhos. Entre os anos de 1540 e 1547 poucos são os documentos que dão notícias de Palladio em Vicenza, por isso deve-se supor que grande parte daquela década foi ocupada por viagens a vários lugares, dos quais depois ele reproduziu ou relembrou os monumentos mais importantes. No Primeiro Livro de seu Tratado, falando das relíquias dos antigos edifícios, ele escreverá que

(...) encontrando-as de muito maior observação dignas, que eu não tinha antes pensado, comecei a medir minuciosamente com suma diligência cada uma de suas partes, das quais tanto tornei-me solícito investigador, não sabendo conhecer ali coisa, que com razão, e com bela proporção não tivesse sido feita, que depois não uma, mas mais e mais vezes transferi-me em diversas partes da Itália e fora dela para poder inteiramente daquelas, compreender como fosse o todo e em desenho reduzi-lo. (PALLADIO, 2002, 1. 1, p. 5, tradução nossa)

No mesmo tratado ele citará monumentos antigos de Verona, Sirmione, Rimini, Ancona, Assisi, Tivoli, Gubbio, Torino, Susa, Pola, Nîmes, Baria, Napoli e de outras cidades, mas sem dúvida as viagens mais importantes foram aquelas feitas a Roma, cinco no total, três das quais em companhia do Conde Trissino. A primeira deu-se no verão de 1541 junto do conde. Desta viagem é noto apenas o itinerário de volta, ocasião na qual Palladio pôde visitar as catedrais de Orvieto e Siena, além de algumas obras de Peruzzi, de Sangallo e de Buonarotti. A viagem de volta seguiu pela Via Flamina que também então começava "na porta Flumentana, hoje dita Del Popolo e passando pela Toscana e pela Úmbria conduzia a Rimini" (PALLADIO, 2002, 1. 3, p. 8-9, tradução nossa). A segunda viagem de 
Palladio a Roma ocorre em 1545. O caminho de ida da caravana passa por Ravenna, Rimini, Ancona, Gubbio, Assisi, Spoleto e Trevi. Da viagem feita em 1547 sabe-se que o arquiteto estava em Roma em maio daquele ano e retornaria a Vicenza em julho e que esse período foi especialmente dedicado ao estudo e à medição dos monumentos antigos. Pela quarta vez Palladio vai a Roma, chamado para a nova igreja de São Pedro. A data não é certa, mas algumas evidências indicam que a viagem ocorreu no final de 1549. Nesta data o conde Trissino encontrava-se de cama, debilitado por sua doença que lhe impedia de caminhar e não pôde acompanhar o arquiteto, mas quase certamente foi devido ao conde que aquele conheceu o papa Paolo III.

Roma acolheu novamente o arquiteto, desta vez em companhia de alguns "amigos venezianos" em 1554. Entre estes amigos estava o intelectual humanista Daniele Barbaro. Barbaro, Patriarca eleito de Aquileia, estava então trabalhando na tradução e nos comentários dos "Dez livros" de Vitrúvio, e por isso tinha necessidade de ver alguns monumentos antigos já visitados pelo arquiteto vicentino, cujos desenhos utilizaria para a própria obra.

Para seus estudos, Palladio precisava conhecer não apenas as localidades dos vários monumentos, mas também sua função e destino, exatamente para poder acertar alguns detalhes úteis para suas pesquisas e suas reconstruções. Desta maneira ele enriqueceu as próprias noções históricas sobre cada monumento, e a partir disso elaborou dois pequenos livretos sobre Roma que seriam publicados naquela cidade por ocasião da viagem de Palladio de 1554: "L'Antichitá di Roma Raccolta Brevemente da gli Autori Antichi e Moderni" e "Descritione de le Chiese, Stationi, Indulgenze \& Reliquie de Corpi Sancti, che sono in la Cittá di Roma". Ambos os livros são guias cuidadosamente elaborados trazendo descrições detalhadas de monumentos e igrejas na cidade de Roma.

Sabe-se que os estudos apresentados no "L'Antichitá" remontam às primeiras viagens de Palladio, sobretudo à de 1547. Neste pequeno livro são apresentadas ao mesmo tempo noções sobre a vida, os usos e os costumes dos romanos e sobre alguns monumentos antigos, como as portas, as termas, os teatros, os foros, os arcos triunfais, os palácios, os templos, o Palácio papal e o Belvedere. Essa compilação foi conseguida através da leitura de diversas obras sobre história antiga e topográfica romana, como o próprio autor cita na introdução do "L'Antichitá" 
(...) me empenhei em recolher o presente livro, com quanta mais concisão eu pude, de muitos fidelíssimos autores antigos e modernos que disso muito escreveram, como de Dionisio Alicarnaseo, [de] Titto Livio, [de] Plinio, [de] Plutarco, [de] Appiano Alessandrino, [de] Valerio Massimo, [de] Eutropio; do Biondo, do Fulvio, do Marliano e de muitos outros. Não me contentei com isto apenas, e também quis ver, e com minhas próprias mãos medir tudo (PALLADIO, 1988)

Sabe-se que Palladio começava suas anotações com croquis elaborados no local, esboços relativos em grande parte às fundações e a detalhes construtivos em forma de "primeiras anotações" dos quais eram elaborados os desenhos "passados a limpo".

"Por sua notação sumária e apressada, às vezes apenas fragmentária, resulta que estes foram executados no local, como se percebe também das precisas medições, por isso deve-se pensar que estes representam a exata consistência dos edifícios visitados". (ZORZI, 1958, P. 27 , tradução nossa). Importante destacar que boa parte das obras visitadas por Palladio encontrava-se em ruínas além de, na época, não terem sido ainda perfeitamente reconhecidos e o rico detalhamento de seus desenhos deve-se mais a uma reflexão sobre o que ele viu do que a um registro direito dos elementos existentes. Palladio, após os primeiros esboços feitos no local, empenhava-se em completar as partes ausentes dos monumentos e dos edifícios tomando como base as medidas das ruínas registradas em seus croquis, nas medidas de outros elementos encontrados no local, como capitéis, bases de colunas, pedaços de trabeação, partes de arquitraves, etc. e nas regras ditadas por tratadistas como Vitrúvio.

Depois dessa primeira reconstrução já em seu estúdio, Palladio passava a limpo seus desenhos, reconstruindo o inteiro monumento, elaborando plantas, cortes, elevações e detalhes exatamente como se estivesse elaborando um novo projeto. E de certa forma ele realmente estava. É como se, a partir de elementos conhecidos - in loco ou através de livros - ele tivesse a liberdade de remontar um quebra-cabeças com as peças que julgasse melhores. A partir destes estudos, Palladio identifica alguns elementos que, como partes, estarão comparecendo e sendo recompostos em suas obras, como é o caso do uso das ordens, dos frontões, da hierarquia entre os cômodos, de elementos de cobertura, abóbadas, janelas, sem falar da simetria ${ }^{2}$. Estes elementos foram escolhidos pelo arquiteto a

2 A palavra simetria é aqui utilizada como foi usada por Vitrúvio em seu Tratado, ou seja como sinônimo de correspondência, ou seja uma concordância uniforme entre a obra e suas partes. Neste ponto de seu texto, o tratadista romano faz uma comparação direta com as proporções do corpo 
partir das reconstruções dos antigos edifícios romanos feitas por ele e seriam utilizados em contextos diferentes dos originais. Exemplo disso é o uso da simetria e da existência de um eixo central nos projetos palladianos de vila. Escavações demonstraram que na arquitetura de habitação os romanos usavam quase sempre plantas livres e que a simetria e a hierarquia das partes eram uma exceção, ao contrário dos edifícios públicos, especialmente os de idade imperial. Sobretudo as termas deste período aproximavam-se do ideal de Palladio. De fato, estes eram a única categoria de edifícios antigos que pudesse oferecer-lhe soluções para muitos de seus problemas de composição. Os imponentes conjuntos imperiais construídos a partir do tempo de Tito e Trajano, século I d.C., se desenvolvem em torno de uma grandiosa progressão de espaços dispostos ao longo de um eixo. Provavelmente estas aulae ocupavam o núcleo central do complexo não porque tivessem uma preeminente importância funcional, mas pelo fato de serem constituídas por imensos ambientes com coberturas em abóbada, a cuja existência estrutural melhor se adequa uma disposição central. A distribuição dos volumes era determinada mais por suas dimensões que por sua importância funcional. Ao estudar os restos da termas mal conservadas ou em parte ainda sepultadas, como as de Agrippa, Palladio registrava fielmente em croquis executados in loco aquilo que via, e neste caso não havia absolutamente certeza de que o esquema resultante fosse simétrico. Mas uma vez de volta ao seu estúdio, o arquiteto reconstruía o desenho; dele muitas vezes desapareciam elementos sobrevividos nas ruínas e o edifício ganhava uma configuração rigorosamente palladiana. No caso de monumentos melhor conservados, cujo entendimento global ainda é possível através de vestígios de muros, o mestre apresenta-os em seus desenhos através de seções escolhidas que tendem a fazer parecer a distribuição mais palladiana do que realmente não fosse. Isso se aplica também à organização externa dos volumes. Os romanos preocupavam-se muito com a criação de uma seqüência de composição que criasse espaços internos com volumes interessantes, mas pouco cuidavam diretamente dessa composição na parte externa do edifício. Os desenhos de Palladio trazem destes monumentos rigorosas e harmoniosas composições volumétricas nas fachadas e nas perspectivas, estudando um modo de aglomerar os espaços em torno de um núcleo

humano, em que a correspondência - ou simetria - entre o pé, a palma da mão, os dedos e as demais partes resulta num conjunto perfeito. 
central. $\mathrm{Na}$ arquitetura romana o mestre procurou, sobretudo, os métodos para organizar e integrar certos complexos de espaços e de massas, especialmente em composições centradas em torno de uma zona axial que continha os ambientes mais importantes. Como dito anteriormente, a partir de todos estes estudos ele identifica elementos que como partes estarão comparecendo e sendo re-compostos em seus trabalhos. Mas se de um lado a teoria palladiana e seu modo de composição seguem a teoria de Vitrúvio, seu principal objetivo ao estudar as ordens era o respeito às leis da estática determinadas pela gravidade aplicadas às construções em alvenaria.

Palladio parece estar interessado nos elementos da antiga arquitetura romana mais pelo que eles representam visualmente do que exatamente porque atendam de uma maneira ou de outra ao decoro ${ }^{3}$, à relação direta entre o uso de uma ordem à finalidade do edifício, posicionamento exemplificado pelo uso de um elemento da arquitetura religiosa - a cúpula - em projetos de residências ou ainda, pelo que diz respeito a habitações, o uso de um pódio que eleva o volume da edificação como os romanos faziam com seus templos.

Palladio opõe-se ao gosto clássico da Antigüidade e do Renascimento florentino e romano na medida em que conserva elementos arquitetônicos da preceptística romana, mas dispõe o mesmo elementos em diferentes situações ou elementos diferentes em similares situações de espaço. Alguns teóricos, como Francesco Milizia (1768, p. 277 apud ARGAN 1999, p. 400) ${ }^{4}$, para quem "todo elemento tem uma tarefa precisa na indicação do espaço e permanece ligado a essa função espacial” e para quem os arquitetos gregos e romanos teriam alcançado, fixando seu cânone nas ordens, "a razão da arte, a beleza pura, a coerência bela de partes belas, representação absoluta do espaço mediante o valor construtivo do relevo plástico" consideram Palladio um iconoclasta dessa beleza pura, por justapor os elementos por sua beleza abstrata de coisas em si. Elementos

\footnotetext{
3 Decoro foi utilizado por Vitrúvio em seu tratado ao falar no aspecto do edifício em seu De architectura libri decem. Para ele, nenhum elemento da construção pode estar num determinado lugar sem razão, ou seja, o edifício tem que representar da melhor forma qual sua finalidade e para quem foi construído. Faz-se aqui uma relação direta com as ordens gregas. Vitruvio cita como exemplo os templos dedicados a Minerva, Marte e Hércules, que devem ser construídos segundo a ordem dórica, ou seja, a ordem que melhor representa a característica de força destes deuses. Já para Vênus, à qual correspondem obras delicadas e ornadas com flores se utilizará a ordem coríntia. Para os deuses como Juno, Diana e do Padre Baco, cujo caráter concorda mais com a severidade e solidez dórica que com a delicadeza coríntia construir-se-ão templos jônicos.

${ }^{4}$ MILIZIA, Francesco (1768). Le vite de' più celebri architetti. Roma: s.n.
} 
como colunas, ordens, entablamentos, ganham um valor na arquitetura palladiana que é próprio deles: eles passam a ser os criadores do espaço.

Palladio torna-se assim um criador do classicismo, como citado por Argan (1999), não histórico. A forma antiga é para ele eterna e o processo que permite reconstruí-la é antes um processo lógico e gramatical do que um processo de pesquisa sobre os dados. A forma adquire, como citado acima, um valor de coisa em si e passa a funcionar numa obra assim como as palavras funcionam numa frase, podendo ser reorganizados de maneiras diferentes, formando discursos diferentes, mas sempre lógicos. Seu princípio fundamental é: "Não é proibido ao Arquiteto distanciar-se algumas vezes do uso comum, desde que sua variação seja graciosa, e tenha algo de natural" (PALLADIO, 2002).

Palladio toma para si aquilo que alguns autores chamam de licenza, no sentido de evasão das regras ou de exercício de autonomia de juízo. Nesse momento é como se o arquiteto passasse a ter um alcance ainda maior, que não se limitava ao arranjo correto de elementos arquitetônicos pré-definidos, mas entram em cena seu engenho, fantasia e graça e outras constantes intrínsecas à personalidade do arquiteto. A obra arquitetônica não se propõe mais a representar ou construir um espaço, se coloca como objeto produzido pelo homem e para o homem.

No âmbito da palavra clássico existem, portanto, dois aspectos do engenho de Palladio que exprimiam ao mesmo tempo a relação deste arquiteto com o passado romano e sua atitude projetual. $\mathrm{O}$ primeiro é a preocupação com o estabelecimento de regras de acordo com Vitrúvio e com os levantamentos das ruínas feitos in loco, o segundo é a atração que a possibilidade de subverter estas regras exerce sobre a imaginação de Palladio.

A leitura simultânea dos textos e dos projetos de vila de Andrea Palladio - sobretudo daqueles por ele publicados em seu Tratado - nos revela a atualidade da contribuição desse arquiteto. Palladio ensina o valor das regras e das tipologias na elaboração de uma idéia, mostra como um 'sistema' arquitetônico pode ser perfeitamente compatível com a capacidade de invenção e, em certos casos, pode ainda subverter ou mesmo anular as regras. Palladio projeta segundo fórmulas fixas, mas sua sensibilidade para as relações tridimensionais, assim como o seu desprezo pela exata repetição de soluções já experimentadas e o sentido que desenvolve na exploração das possibilidades específicas de cada sítio, cliente ou problema, fazem com que cada obra se torne diversa. É rico e constante o diálogo que estabelece entre uma e outra arquitetura, diálogo entre duas épocas, entre os 
pressupostos da arquitetura clássica e o fazer de sua arquitetura, entre o passado e o presente.

\section{Palavras, frases, discursos: a poesia das villas}

"Vila" para os escritores da antiga Roma não era um conceito arquitetônico nem muito menos artístico, mas uma afirmação de caráter econômico. A vila compreendia todo o poder, da terra à habitação dos empregados, dos edifícios necessários à organização de uma propriedade rural à casa do patrão. Distinguia-se uma "vila rustica" e uma "vila urbana": esta última destinava-se a acomodar o patrão durante sua permanência na propriedade e era constituída por poucos cômodos com um modesto "banheiro". Nasce assim a vila, diferenciada da domus urbana e da casa colonial. Esta última tende a ser simples em sua estrutura e a conservar as formas tradicionais que não implicam na intervenção de um projetista.

A maior parte das vilas romanas não era absolutamente clássica: os exemplos antigos são normalmente despidos da simetria axial, do rigor e das proporções racionais. Os volumes que as compõem parecem ter sido construídos ao longo do tempo conforme as necessidades funcionais. $\mathrm{Na}$ vila de Adriano em Tivoli, por exemplo, cada parte tem um significado por si só e não se uniformiza materialmente com as estruturas contíguas mesmo que entre estas possa existir alguma ligação visual. Foram os arquitetos renascentistas que conferiram a estas construções a simetria e a organização clássica, com imposições de regras de ordens, que permanecem ao menos até o século XVIII.

No século XV no Vêneto existem dois tipos de vila: aquela dividida em casa, anexos rurais e pombais. Durante a Guerra dei Cambrai (1509-1517) casas e infra-estruturas rurais foram bastante danificadas. Para alcançar os precedentes níveis de prosperidade o processo foi lento e aconteceu apenas nos anos 40, com o crescimento do mercado urbano dos gêneros alimentícios e a decisão em nível governamental de libertar Veneza e o Vêneto da dependência do grão importado, e especialmente daquele que provinha do sempre ameaçador Império Otomano. Esse enorme investimento em agricultura e nas infra-estruturas necessárias à produção agrícola acelera o passo. Durante décadas os proprietários de terras tinham adquirido constantemente, sob o estável governo veneziano, pequenas 
propriedades. Os investimentos em irrigação e na bonificação por meio de drenagem multiplicaram a renda dos ricos latifundiários.

Em termos de arquitetura as exigências também mudaram. Tornaram-se necessárias mudanças na construção e na organização da vila que o padovano Andrea Palladio reconhece, interpreta e encarna muito bem. Seus desenhos reconhecem implicitamente a não necessidade de um "palácio de campo" igual àqueles da cidade, mas as propriedades também não poderiam continuar hospedando o dono e seus convidados modestas e simples casas coloniais. Ele entende que algo menor, muitas vezes com um único piso habitável, era adequado como centro para controlar as atividades produtivas - das quais provavelmente deriva a maior parte da renda do proprietário - e para impressionar os inquilinos e os vizinhos, além de entreter os hospedes mais importantes. As fachadas de suas vilas, dominadas por frontões com as insígnias do dono, anunciavam sua presença e dominação do território, conferiam à vila uma grandiosidade mesmo que o tamanho do edifício fosse reduzido. As logge destes ofereciam um lugar sombreado para ler, estar, passear, para apresentações musicais e outras atividades.

Internamente, Palladio distribuía as funções tanto verticalmente quanto horizontalmente. Cozinhas, dispensas, lavanderias e porões encontravam-se no térreo; o espaço sob o telhado era usado para armazenar o grão, o produto mais precioso da propriedade, alem de funcionar como isolante térmico para os ambientes abaixo. No piso principal, habitado pela família dominical e por seus hóspedes, os cômodos mais públicos, como a loggia e a sala, encontram-se no eixo central, enquanto à direita e à esquerda estavam os outros cômodos, daqueles grandes retangulares, passando pelos quadrados até os pequenos retangulares. O pátio abrigava anexos rurais, torres para os pombos, fornos para o pão, galinheiros, estábulos, habitações para os empregados e para a criadagem, cômodos para fazer o queijo e porões para espremer a uva. Já no século XV usava-se criar diante da casa um pátio, também chamado de corte, com um poço, separado do resto do pátio de serviços com seus anexos, os animais e os espaços para bater o grão. Jardins, hortas de verduras e especiarias, tanques para os peixes e o pomar eram todos agrupados e localizados no interior de um muro limítrofe da propriedade.

Palladio encontrou inspiração nos grandes complexos antigos que parecem com moradias de campo circundadas por suas dependências, ou que talvez ele realmente acreditava serem complexos residenciais, como por exemplo o templo Ercole Vincitore em Tivoli, por ele desenhado. O 
arquiteto estava antes de tudo à procura de um vocabulário expressivo e formal, mas também da evolução histórica das formas antigas.

Em sua obra é constante o diálogo que se estabelece entre o pensar e o fazer na obra, entre uma e outra arquitetura, entre um ideal e uma prática. Diálogo entre duas épocas, entre os pressupostos da arquitetura clássica e o fazer contemporâneo dessa arquitetura.

\section{Bibliografia}

ACKERMAN, J. S. (1992). La Villa. Torino: Einaudi.

ACKERMAN, J. S. (1972). Palladio. Torino: Einaudi.

ARGAN, G. C. (1999) Clássico e Anticlássico. O Renascimento de Brunelleschi a Bruegel. São Paulo: Companhia das Letras.

GROS, P. (1996) L'Architettura Romana Dagli Inizi del III Secolo a.C. alla Fine dell'Alto Impero. Milano: Longanesi \& $\mathrm{C}$.

LANCHA, J. J. (1993) Do Projeto ao Objeto, Do Objeto ao Projeto. Tradução da Tradição. A arquitetura das vilas de Andrea Palladio. Dissertação (Mestrado) - Escola de Engenharia de São Carlos, Universidade de São Paulo, São Carlos, 1993.

LANCHA, J. J. (1999) - A Construção de uma Idéia: Palladio, Le Corbusier e Terragni. Tese (Doutorado) Universidade de São Paulo, São Paulo, 1999.

PALLADIO, A. (1988). L'Antichitá di Roma raccolta brevemente da gli autori antichi e moderni. In. PUPPI, L. (org.) Andrea Palladio, scritti sull'architettura (1554-1579). Vicenza: Neri Pozza..

PALLADIO, A. (2002) I Quattro Libri Dell'Arcbitettura. Milano: Hoelpli.

PUPPI, L. (1988) Andrea Palladio. Milano: Electa.

SUMMERSON, J. (1997). A Linguagem Clássica da Arquitetura. São Paulo: Martins Fontes.

ZORZI, G.G. (1958). I disegni delle antichitá di Andrea Palladio. Venezia, [s.n.]. 